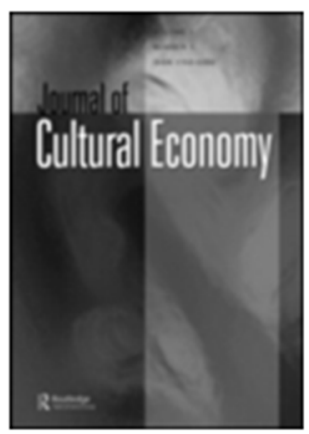

The infrapolitics of cultural value: cultural policy, evaluation and the marginalisation of practitioner perspectives

\begin{tabular}{|r|l|}
\hline Journal: & Journal of Cultural Economy \\
\hline Manuscript ID & RJCE-2015-0008.R2 \\
\hline Manuscript Type: & Original Article \\
\hline Keywords: & $\begin{array}{l}\text { cultural value, cultural impact, instrumentalisation, cultural evaluation, } \\
\text { infrapolitics }\end{array}$ \\
\hline \multicolumn{2}{|c}{} \\
\hline
\end{tabular}

SCHOLARONE ${ }^{m}$

Manuscripts 


\title{
The infrapolitics of cultural value: cultural policy, evaluation and the marginalisation of practitioner perspectives
}

\begin{abstract}
This article is about the politics of cultural value. It focusses on the representations of value that exist in the epistemologies and methodologies of cultural impact evaluation and the discrepancies between these official discourses and the discourses that correspond to cultural practitioners themselves. First the article outlines the critique of dominant forms of cultural impact evaluation, particularly the instrumentalisation of culture. In the second half of the article we draw upon qualitative research conducted with arts practitioners in the East Midlands region of England during 2013 and 2014. In so doing we introduce the concept of the 'infrapolitics' of cultural value that draws on the work of radical anthropologist James C. Scott (1992).
\end{abstract}

The central argument is that representations of cultural value are discursive constructions constituted through the epistemologies and methodologies of cultural evaluation, and that there are key differences between these dominant discourses and the discourses of value of cultural practitioners themselves. One important although overlooked element of the significance of cultural value is therefore as a record of the performance of power within the cultural sector, an 'official transcript' that represents dominant discourse of cultural value in opposition to the 'hidden transcripts' that correspond to cultural practitioners. We argue for a research agenda that represents cultural value from practitioners' point of view.

Keywords: cultural value; cultural impact; instrumentalisation, cultural evaluation, infrapolitics, hidden transcripts

\section{The problem: official representations of cultural value and the voice of practitioners}

In a funding environment where cultural subsidy must demonstrate a return on investment in competition with other kinds of social and economic interventions, the evaluation of the effects of cultural activities which have had direct or indirect public subsidy is seen as paramount. This is of particular importance at the present time with arts and cultural organizations facing the most challenging funding environment for a generation. In the UK, 
the austerity agenda embarked upon in 2010 by the Conservative and Liberal Democrat Coalition Government is an overarching political-economic programme with very little nuance that informs all areas of public policy, including the arts, cultural and creative industries. From under the cloak of financial-economic crisis, the UK is currently submerged in a process in which many of the remaining institutional and ideological architecture of social democracy is being dismantled and reconstructed through the values and practices of neoliberalism. Amid this chaos, the supported cultural sector is charged with making a fresh case in order to legitimise a share of a shrinking pot of state spending. The value of culture is currently up for debate and definition by academics, in various cultural institutions and at the Department for Culture, Media and Sport. This has resulted in the development of the CASE programme and database ${ }^{1}$, a number of large scale reviews of the existing evidence (eg., CASE 2010, CASE 2010) and several position papers and reviews by leading cultural policymakers and academics (eg., Bakhshi, Freeman et al. 2009, O'Brien 2010). The 'cultural value debate' has also been the subject of an Arts and Humanities Research Council (AHRC) funding initiative since 2010 and a major initiative led by the University of Warwick. ${ }^{2}$ There is, therefore, a felt need for innovation in the understanding of cultural value, the collection of cultural impact data and the ways this data is analysed, interpreted and communicated; a new methodology which is able to speak to government in a new language. There is also, potentially, a space opened up in which a new, progressive politics of cultural practice and participation might emerge, one which is conceived in opposition to the emerging norms of austerity and neoliberal capitalism.

What we have in the cultural value debate is an evaluation of different, competing representations of value and their corresponding discourses. It is, then, an inherently political debate about vested interests and power relationships. This article is about the politics of cultural value. It focusses on the representations of cultural value that exist in the 
epistemologies and methodologies of cultural impact evaluation and the distance that exists between these official discourses of value and the discourses of value that correspond to cultural practitioners themselves. Its central argument is that representations of cultural value are discursive constructions that correspond to specific social groups. The hypothesis is that in contemporary official representations of cultural value, the discourses that correspond to cultural practitioners themselves are marginalised. This is part of a longer process of the commodification and instrumentalisation of cultural policy that has been written about elsewhere (McGuigan 2005, Grey 2007, Newsinger 2012, Hesmondhalgh, Nisbett et al. 2014, Newsinger 2015, Banks 2015). Our concern here is, firstly, to argue for a research agenda that understands and represents cultural value from practitioners' point of view as a corrective to a cultural policy increasingly conceived within a top-down instrumentalised paradigm. Debates around cultural impact and instrumentalism are outlined in the first part of the article.

In order to test the hypothesis, in the second half of the article we draw upon a qualitative research project that consisted of eight in-depth interviews and a focus group with 'participatory arts' practitioners in the East Midlands region of England during 2013 and 2014. This group of cultural practitioners occupy a specific role in the cultural sector, one which is characterised by a highly ambivalent relationship with the instrumentalisation of cultural practice, and the associated processes and technologies of performance management and evaluation. In order to explore these ambivalences we adopt an approach that responds to Kaszynska's (2015) call for social science of cultural value to refocus on qualitative empiricism through methodologies which represent subjective experience. Our contribution to this research agenda is through the application of the concept of 'infrapolitics' that draws on the work of radical anthropologist James C. Scott (1992), particularly the importance of the reconstruction of the 'hidden transcripts' of subordinate social actors. What emerges is a 
discourse of value characterised by complexity that does not neatly map onto the intrinsicinstrumental dichotomy that animates cultural policy debates. The conclusion draws together the implications of this for cultural policy debates and for the social science of cultural value.

\section{The politics of cultural value}

The term 'cultural value' is of central importance to longstanding debates in cultural policy, despite being a relatively empty, depoliticised and even actively mystifying signifier. The primary distinction between different understandings of cultural value in the cultural policy literature is between value that is intrinsic to cultural artefacts and cultural activity, and value that accrues through the instrumentalisation of culture towards other ends, perceived as external to the cultural field. Indeed, this distinction has animated debates in this area to a considerable degree, with, on the one side, the cultural philistines of administrative and technical cultural policy who only recognise value when it can be expressed in monetary terms and, on the other, the economically illiterate, probably elitist and metropolitan, figures of the romantic artist and ivory tower intellectual, unwilling to recognise the realities of competing claims on tax revenue and legitimate democratic accountability. Rather than take sides within this debate or critique the efficacy of certain versions of cultural value over others, we adopt a perspective that sees evaluation epistemologies and methodologies as discursive constructions that are reflective and constitutive of power relationships within cultural institutions and the wider political economy. What follows contextualises this debate.

The narrative of the instrumentalisation of the arts and culture is now well established in cultural policy literature (for example, Grey 2007, Vickery 2007, Belfiore and Bennett 2008, Crossick and Kaszynska 2014, Banks 2015). Its origins are usually identified in the 1980s with Thatcherism and a general hostility to the state and to arts subsidy in particular, 
through to the 1990s and Blairism with the adoption of New Public Management approaches to public services and the associated emphasis on measurable targets, monitoring and evaluation, and top-down managerialism and control.

For example, Eleanora Belfiore traces the origins of the instrumentalisation of arts funding to the twin forces of postmodernism and Thatcherism which questioned the very basis of arts funding (Belfiore 2002). As a response,

the arts sector decided to emphasize the economic aspects of its activities and their alleged contribution to the wealth of the nation. This was originally a defensive strategy of survival, aimed at preserving existing levels of cultural expenditure. The hope was that, if the arts sector (now referred to as the "cultural industries") could speak the same language as the government, it would perhaps have a better chance of being listened to (Belfiore 2002: 95).

In Clive Grey's account, the instrumentalisation of cultural policy is explainable largely as an example of 'policy attachment' (Grey 2002), the process whereby:

the lack of political interest and power associated with the sector, particularly at the local level, leads to the development of policy "attachment" strategies whereby funding for the sector can be gained by demonstrating the role that it can play in the fulfilment of the goals of other policy sectors. In this case an instrumentalisation of arts and cultural policy is the consequence of a conscious strategy pursued by policy makers to generate the support that is needed for them to pursue their own objectives, and the development of instrumental forms of policy is a side-effect of the intention to produce "effective" (however this may be defined, and whoever it is being defined by) cultural and arts policies in the first place." (Grey 2007: 206)

For Grey, the specific forms that 'effective' cultural policy interventions took during this period can be understood as a process of 'commodification'. That is, the "commodification of public policy through the creation of the ideological conditions within which exchange-value becomes increasingly favoured over use-value in the creation, implementation and evaluation of policies" (Grey 2007: 203). The increasing demands for economic and social justifications for cultural funding led to the 'attachment' of the arts to such diverse policy goals as economic growth, the reduction of public debt, urban regeneration, remedying of social exclusion, and more individualistic benefits such as personal development, employability and 
community empowerment (Grey 2007). This process of commodification has continued to the point where, in the words of Mark Banks, "some of the more recent UK policy discussions and interventions [...] make little or no mention of the non-economic values and capacities of art and culture at all.” (Banks 2015: 39)

The consequences of instrumentalisation in arts and cultural policy are myriad and intensely debated (see Caust 2003, Mirza 2007, Gibson 2008, Bunting 2010, Kahn 2010, Walmsley 2012, Hewison 2012). For example, the emphasis on wider social and economic 'impact' has been accused of contributing to a lack of focus on quality, leading to repeated charges of cultural philistinism (Holden 2004). Particular criticism has centred on the methodologies of cultural evaluation and the phenomena of the impact evaluation study through which arts and cultural organisations seek to demonstrate that instrumental targets are being met. There have been sustained critiques of methodologically unsound impact evaluations, with reports often assuming a cause-effect link between cultural participation and a change in a predefined indicator without isolating other variables (Merli 2002). The widespread use of invalid statistical evidence to support claims about the impacts of the arts and culture has led many to dismiss impact evidence as little more than advocacy (Belfiore, 2009). In the words of Bruno Frey:

Arts people take the artistic value as given. They see no need to establish that it contributes to human welfare. They take it as a matter of course that the support of the arts belongs to the essential tasks of governments. The need to activate decision makers actually to undertake artistic projects is seen as the real problem. They feel that the decision makers can be best convinced to become active when it is demonstrated to them that the artistic project yields large economic benefits. Impact studies serve to prove this claim 'scientifically'. (Frey 2008: 262)

Critiques such as these have pushed epistemologies of cultural value in two directions. On the one hand they have led Frey and others to call for the adoption of the more well-established methodologies of economic valuation by the cultural sector, so as to make a more credible case for arts funding. This identifies the main problem in cultural impact evaluation as the 
lack of a suitably robust, valid and therefore persuasive case. For example, in a DCMSsponsored report, David O'Brien notes that "in recent years there has been recognition, both within central government and in parts of the publically funded cultural sector, of the need to more clearly articulate the value of culture using methods which fit in with central government's decision-making." O'Brien argues that "the cultural sector will need to use the tools and concepts of economics to fully state their benefits in the prevailing language of policy appraisal and evaluation". (O'Brien 2010: 4) O’Brien advocates the development of methods to "make sure the value of culture can be narrated within a cost-benefit analysis." (O'Brien 2010: 16) Institutions such as NESTA and particularly its head of policy and research, Hasan Bakhshi, have been consistently critical of the reluctance of arts institutions to adopt the methods of economic valuation (Bakhshi, Freeman et al. 2009, Bakhshi 2012).

On the other hand, the critique of cultural evaluation has led some to reject the search for objective quantification altogether, advocating the refocusing cultural value upon subjective experience and the phenomenological. For example, for Patrycja Kaszynska the instrumentalisation of cultural policy has "not only severed any meaningful connection between cultural value and experiences but $[\ldots]$ threatened the internal coherence of the notion altogether". (Kaszynska 2015: 2) Kaszynska argues that social science of cultural value should reject the positivism embodied in impact evaluation and instrumentalisation in favour of the qualitative empiricism of the subjective experience: "cultural theory and theories of cultural value more specifically have to revisit the suspicion of experiences and embrace phenomenological methodology.” (Kazynska 2015: 2) Similarly, Ben Walmsley has argued that:

\footnotetext{
we find ourselves at a turning point in history, where traditional economic models are being questioned and that this provides a historic opportunity for the arts sector to unite to reject the measurement-obsessed dogma of public policy and develop a more creative approach, which puts the public back into value and the value back into evaluation (Walmsley 2012: 332).
} 
We share with Kaszynska (2015) and Walmsley (2012) the concern with reconstructing the prism of subjective experience and the representation of cultural value in "the terms used by social agents themselves." (Kaszynska 2015: 5) However, Walmsley (2012), Kaszynska (2015) and many of the contributors of the Cultural Value Project ${ }^{3}$ are primarily concerned with capturing and investigating the cultural experiences of audiences and participants. Little research has explored cultural value from the perspective of the cultural practitioners themselves (Woddis, 2014). Indeed, this is a peculiar blind spot in debates on cultural value and instrumentalism, one that impoverishes our understanding.

\section{The infrapolitics of cultural value}

Central to understanding the politics of the cultural value debate is moving beyond the intrinsic-instrumental dichotomy towards the recognition of the multiple and ambivalent functions of the methodologies and epistemologies of cultural policy. Here we draw upon the work of Judith Butler on the performativity of the economy (Butler 2010); the constitutive role of the convergence of certain practices, expressions and activities to produce the 'effect' of a monolithic unified ontology. In this case, it is the performativity of methodologies and epistemologies of cultural evaluation that converge to produce a knowable and unified onotology of value within the cultural sector. Similarly, Moor and Lury (2011) explore the "ways in which different constructions of value" become "embodied in measurement" and how the "relations between measurement and valuation configure and reconfigure the distribution of agency" (Moor and Lury 2011: 450).

Most commentators on the instrumentalisation of cultural value note the extent to which the methodologies of cultural impact evaluation redistribute agency away from practitioners and marginalise practitioner perspectives (see Caust 2003, Belfiore 2004, Mirza 
2007, Woddis 2014). Moor and Lury's work, however, throws light upon the ways in which social actors can adapt and modify existing metrics in order to better suit strategic interests (Moor and Lury 2011). The practices and processes of measurement and evaluation should be conceived, they argue, as highly productive "calculative spaces" that constitute and distribute agency across all social actors, and not simply as restrictive and deterministic (Moor and Lury 2011: 450). The key questions for understanding the performativity of cultural value for practitioners are: to what extent are dominant epistemologies adopted by practitioners themselves? How do these constitute, structure and delimit practitioners' own understandings of cultural value, and set agendas and limitations upon practice? And how are they adapted and modified by practitioners themselves? The politics of dominant versions of cultural value, the extent of their role in setting cultural agendas, legitimising and determining the possibilities for cultural practice and participation in conscious opposition to opposing models is more important than is often recognised and should be a key focus for research.

One way to measure the extent and character of this function is to explore the discrepancies between cultural practitioner's own understandings of cultural value and dominant conceptions, between official methods used to measure cultural impacts and informal measures, and between discourses of value that exist in cultural policy more generally. Through understanding the differences between practitioner conceptions of cultural value and official conceptions, we can judge such things as the extent of the centralisation of cultural authority during the period, and the relative power of cultural practitioners in their collective address to the institutions of government. This research agenda draws upon the anthropology of James C. Scott (1992). Scott argues that the public representation of interactions between dominant and subordinate social groups rarely fully represents the discourse of the subordinate. Scott (1992) calls these public representations the 'official' or 'public transcript'. 
The construction of the public transcript is a dialectical process. Hegemony is never absolute or static, but performed repeatedly; the consent of the subordinate is not agreement, not absolute, but a tactic, a strategic accommodation to dominant discourses. The discourse of the subordinate social group therefore remains, more or less, implicit, a 'hidden transcript'. Scott (1992) calls the sum of the interactions between the official and hidden transcripts 'infrapolitics'. A key point for the researcher is that by "assessing the discrepancy between the hidden transcript and the public transcript we may begin to judge the impact of domination on public discourse." (Scott 1992: 5)

The techniques and technologies of cultural evaluation play a performative role in the generation of a public transcript of culture in that they rehearse, confirm and validate the domination of certain values in cultural practice. Cultural organisations take part in these rituals - grudgingly, enthusiastically, and so on - demonstrably conforming to dominant discourses of value in order to construct and maintain space to manoeuvre. One important although overlooked element of the significance of impact evaluation is therefore as a record of the performance of power within the cultural sector, a public transcript that represents dominant discourses of cultural value in opposition to the hidden transcripts that correspond to cultural practitioners. As Scott says: "The capacity of dominant groups to prevail - though never totally - in defining and constituting what counts as the public transcript and what as offstage is $[\ldots]$ no small measure of their power" (Scott 1992: 14). Conversely, the extent to which organisations and individuals modify and adapt dominant methodologies of cultural value for strategic interests demonstrates the limitations on such power. As Moor and Lury comment, "It is here that new calculative spaces are constructed, and where new figurations of sociality and agency can be discerned" (Moor and Lury 2011: 448). 


\section{Hidden transcripts}

But how might we seek to uncover the hidden transcripts of cultural practice? Our research conducted eight interviews and a focus group with participants (henceforth 'interviewees') drawn from four organisations based in the East Midlands region of England. The interviews were designed to generate practitioner understandings of cultural value and adopted principles of the Critical Incident Technique (CIT); the focus group was designed to explore the evaluation practices and understandings of the participating organisations. ${ }^{4}$ Our interviewees primarily worked in the participatory arts sector, or within arts organisations whose primary focus was not participatory arts, but that conducted work that could be considered participatory arts alongside their primary activity. This includes a theatre and an annual cultural festival.

Many (although not all) of our interviewees considered themselves practicing artists alongside their participatory arts work - indeed, this was explicitly considered essential to doing 'good' participatory work by one interviewee (ST001). Our interviewee's organisations engaged in a wide range of artistic and cultural activities, including drama/theatre, painting and fine art, music and music production, dance, even cooking. Three of our interviewees were aged 18-29, three 30-49 and two 50-64. Three were male and five female, and all except two were educated to degree level.

This is in line with the known general characteristics of the participatory arts sector (Cox 2014). Many practicing artists work in the participatory arts sector as an important source of income and distinct area of practice, although the status of participatory work is somewhat ambiguous due to its instrumental, social and, to a lesser extent, economic function within cultural policy. Jane Woddis draws a useful distinction between 'insider' groups those regularly consulted by government - and 'outsider' groups - those unwilling or unable 
to gain recognition - in order to conceive of the role of practitioners in cultural policy formation (Woddis 2014). Our interviewees represent a particular 'outsider' group within the cultural sector, one which has been at the sharp end of the instrumentalisation of cultural policy, and therefore provide a distinct viewpoint.

Our interviews sought to elicit the values attached to cultural participation from the practitioner's point of view, and the role of evaluation -both formal and informal - in their practice. We asked interviewees to describe an activity that they had been involved in that was a success and one that was a failure, with these terms being defined in any way that the participant wished. Probing focussed upon three main areas: the environment in which the activity took place, the different people involved, and the object of the activity - the artefact in order to build a rich understanding of the determinants of value from the participants' own perspective. ${ }^{5}$ Data analysis generalised these descriptions of cultural value, exploring the relationships between different factors in the practitioners' self-understandings.

We asked our focus group participants about the sorts of formal impact evaluation practices their organisations employ to represent the value of the work that they do. This produced a great range of different kinds of activities, listed in Table 1.

\section{[Insert Table 1. here]}

These ranged from 'soft', anecdotal forms such as observation, participant feedback, diaries and case studies; to questionnaires and self-assessments; to more quantitative representations based upon media coverage analysis and crime rate analysis. One of the organisations we spoke to had conducted a number of social audits using outside consultants and employed methods of Social Return on Investment in attempts to meet funders' demands for impact evaluation that demonstrate positive instrumental benefits. 
Hesmondhalgh et al's discussion of cultural policy in the period notes that the "techniques of inspection, benchmarking, self-assessment, strategic planning, target setting, key performance indicators and service agreements" are "deeply disliked within the arts and heritage communities, in a way that directly parallels the resentments of teachers, medical professionals and university academics towards similar infringements on autonomy in other institutions" (Hesmondhalgh, Nisbett et al. 2014: 10). Unsurprisingly, many of our interviewees discussed such evaluation and monitoring procedures in similarly negative terms, particularly for being invasive and time consuming. Take this for example, from P005, discussing the evaluation required by funders of a small project: "Yeah, particularly bad, considering that the project was under-it was about $£ 7,500$, the amount of data collection we had to do for it, we pretty much had to take hair samples and dental records from the participants, it was absurd." Or, similarly, from ST002: "particularly in the last kind of 20 years, you'll probably — two generations of young people have kind of got very sick of - and no disrespect here - of people with clipboards asking questions, right?"

Other interviewees expressed ambivalent attitudes towards formal evaluation practices. For ST005, for example, one of the strengths of a 'social audit' was that "for the first time ever we consulted with our staff about what we do." On the other hand, "it was a lot of work, the actual huge big report well who the hell is going to read that? In terms of quantifying it is still more kind of descriptive but it enabled us to pull out nice case studies so yes we could say that $75 \%$ of people think that [our organisation] delivers and gave a five to us delivering our mission but actually that is still not getting an impact so after doing it twice we decided that we didn't want to do it again."

As well as these more grounded, practical discomforts, there were critiques of the limitations of established methods of impact evaluation to fully represent value. The same 
person describes some of these issues in more detail:

We have, and we do use questionnaires with young people where they say 'I think my confidence is whatever' they are deeply problematic and there is a whole problem behind that. How do you authentically, genuinely get from young people where they feel they are starting and where they feel they get, where they ended up and what your intervention has... well we have done that in different ways: paper, going around with a voice recorder, sitting down with young people individually, using iPads, using Facebook. It is all problematic really [...] I would say with the self-assessment and the questionnaires with the participants it is very inconsistent. The only project where I would say we were really able to do it with self-assessment at the beginning and then do it at the end and report back on it and it feels quite robust, we were absolutely forced to do it by a funder.

These problems were explicitly linked towards the nature of project-based funding by a number of participants, such as BD001:

One of the things I feel quite strongly about is it is not quantifiable and it is not a solvable thing but it is about needing a definitive outcome and a definitive end and we work on things that are generally speaking time restrictive to a particular funding stream or organisation requiring particular outcomes which completely belies the fact that human experience is ongoing.

And YT001:

You don't know, none of us do, the impact of even this conversation on us today. The impact can be shown much further down the line of how I deliver some of my work. We don't realise that impact has happened so how can you record that? You can't physically or mentally record that so I don't know it is even going to happen.

The sense of official forms of cultural impact evaluation as inappropriate and invasive topdown management techniques confirms much of the existing critique of New Public Management in the cultural policy literature (see, for example, Hesmondhalgh, Nisbett et al. 2014: 8-10, Belfiore 2004). However, for our interviewees evaluation is not solely about representing cultural value to outside organisations or fulfilling imposed needs of funders. Many of our interviewees, particularly those in more managerial positions, also strongly indicated that evaluation of activities was an important part of self-reflection on practice and contributed to organisational culture. For example, YT001, a theatre manager, "I think it is very much around organisational development, it is about making sure we are achieving what 
we as an organisation feel we should be achieving and so it is very much around getting that feedback so that we can better ourselves and better our provision all the time."

One key idea to emerge is that the emphasis on hard, quantifiable measures as part of a competitive funding ecology is in tension with the more reflexive role of evaluation. At the same time there was a strong sense of self-conscious pragmatism around the necessity of advocacy and the role of evaluation in generating evidence. These tensions and contradictions are well articulated by ST005:

I think part of the problem is being pushed more to satisfy requirements for funding and be able to be competitive really is what a lot of it comes down to. I think we are in danger of losing some of the self-reflection and the evaluation cycle of feeding back and I do feel that that is a bit of danger with some of the impact measurements, how we can keep the balance right because yes we do have to apply for finding and we do have to promote ourselves and it is a competitive environment out there but on the other hand we are not doing it for organisation development and quality purposes and that is crap really.

[...] we are expected to engage with the advocacy agenda which is all about that but generally as a sector collectively I feel we all recognise we need to be being that. It is not just about our individual organisations, it is about in the political environment that we are in, political and economic environment, we need to fight our corner. We need to be able to say this is the value of the arts.

Overall our interviewees are very conscious of the limitations of some of the standard evaluation practices that are common to the sector to represent their own understandings of cultural value. At the same time they also demonstrate a self-consciousness about the need to generate evidence useful in advocacy. In this way, the varied kinds of formal and informal evaluation practices represented in our sample, combined with the multiple functions of evaluation within and outside of organisations, demonstrates both the performative nature of evaluation and its productive capacity. That is, the productive capacity of evaluation “depends less on actors' belief in its objectivity, but rather on its capacity to identify opportunities for agency and further value creation" (Moor and Lury 2011: 452). The sense is of multiple and varied strategic accommodations to a competitive funding environment in 
which culture is instrumentalised towards outcomes external to cultural practice.

In describing examples of arts practice, our interviewees deployed a range of different understandings of value, many of which would fit into the instrumental vs intrinsic dichotomy. Some people articulated the value of culture as inherent to being human and unknowable. For example, ST002:

\begin{abstract}
...there is a need in people to do that stuff and to make things themselves and it doesn't matter how many great new things you've sold, people still want to make stuff [...] people still want to make things themselves, I think it's fantastic, I'm glad that whatever that basic human need or desire or motivation is, is still there, and maybe more so than ever, because it isn't the experience of participating in some kind of group, creating something that is not like buying stuff from a shop or online.
\end{abstract}

The same person described participation in cultural production in the following terms: "there is something else that exists within most people, a desire to do — and out of it, yes you know, it is a buzz, it is just a buzz, it is whatever the correct word for that - it is a great feeling." Cultural value was understood as part of having a creative life, with creative practice as a human need.

Much more prominent than these 'intrinsic' understandings of cultural value as something inherent and ambiguous, however, was the expression of value in more prosaic terms, and particularly in terms of the impact of arts participation on individual psychology. It is individual psychological impacts that featured most heavily in all the expressions of value that we encountered. All those we interviewed recalled examples of positive impact in psychological terms. For example, ST001 describes painting a mural with a group of children:

...none of them would have thought at the beginning of the week that they could do that, really, and could have learned so quickly. And that then, you know, gave them the confidence to go on and do more, you know, continue with what they were doing, really. It just gave them that kind of aspiration I suppose.

Similarly, P005 describes a craft project that took place at a community centre: 
...it was about just opening up their ideas as well, because a lot of them had never worked, because they were relatively young mums, most of them were sort of 20 to 23ish, and their children were about 4 or 5 , so they were coming to a point when it's like, right so you could be looking for work soon, but-yeah, so we all just wanted to open up their ideas of what they could do, and a lot of it was about their sort of personal, social development as well, getting their confidence up and-confidence that they could do something, and creating something for themselves.

'Aspiration', 'confidence', 'personal development', 'creativity' - these are the kinds of descriptors most frequently used to represent the value of cultural practice by almost all of the people we spoke to. This may be a reflection of the internalisation of instrumentalism as the value of arts practice, particularly in participatory contexts, and in this way can be theorised as a performative expression of the dominant transcript. However, it is just as likely that the perceived capacity of cultural practice to have external positive impacts upon participants is central to the hidden transcripts of our interviewees. Instrumental value - value that accrues through the instrumentalisation of culture towards non-cultural ends - is not, therefore, an imposed outside constraint for the participatory artists that we spoke to. Crucially, individual psychological and social impacts were not seen as exclusive or in tension with more intrinsic impacts. In fact, it is the intrinsic-instrumental distinction itself that was most alien to our interviewees' understandings of value. In our sample there is no tension between instrumental and intrinsic notions of cultural value.

Perhaps unsurprisingly, artefactual determinants - those intrinsic to the work themselves - were a minor element of the discussions of value in our sample, and almost never cited independently of other variables. Take this discussion of curating an art exhibition by a manager:


motivation comes from doing good work and getting the outcome, if they, they could be as motivated and cohesive as a team as they like, but if they put on a crap show, and they stand back and go "that looks crap and no-one's bought anything", they're not going to be motivated to carry on being involved. (P005)

Here, putting on a 'good show' is part of sustaining and motivating a team of volunteer 
curators, and both are equally important to the generation of value.

On the other hand, here is an example of a very specific instrumental piece of theatre, for which the artefactual qualities are central to the generation of value:

I did a project with them which was joy riding, like trying to discourage at risk young people from stealing cars and taking them for a ride, and essentially that performance took place in a fire station, started with about 15 minutes of performance, some young people, supposed to be in a park, and some of them decided they're going to go off to steal a car, and then basically you hear the noise of a car crash, the shutters open up, and there's a mountain of cars with members of the cast with bones sticking out and all the gory kind of makeup, a fire engine turns up and starts cutting them out of the car, ambulance turns up, starts lifting them out, police turn up and start arresting people, actual fire engine and ambulance pulls up, all the works, and I mean, some of those kids like-it was pretty graphic and pretty extreme, we had people who fainted. (P002)

Many of our interviewees highlighted the importance of the social determinants of value, and this was particularly prominent in discussions of participatory arts work in communities. For example, ST002 highlights the central importance of the co-creation of value in participatory arts practice: “you can't get whatever level of quality of work out of the collective until you've got a collective, and then you've got a way of working that's kind of, you know, mutually acceptable.” The same interviewee drew a strong distinction between this form of practice and that of an individual artist:

ok so local artist gets 40 grand to make a sculpture in town, fine, you know, they're going to stand and fall by their work, it's not what we do, it's not-it doesn't include anyone but that artist's ideas, and you know, that's fine, but they call that public art, well I don't. It's got nothing to do with the public, it's private art on public show. That's what a gallery is, it's private art on show to the public, what say do the public have on what's in your show? None.

This highlights the difference in relative importance of variables depending on the kind of cultural practice in question to the generation of cultural value.

One of the most striking things to emerge from our interviewee's descriptions of value was the interaction of multiple variables as central to the generation of value. A good example of this is given by ST004, which we quote at length: 
On a personal level, it's what I love-I-you know, I was a musician, I was an engineer, a sound engineer for bands, and that's what I started off doing, so-on a personal level I'm doing what I love doing, you know, getting young people-making music and getting young people to make music and seeing that-seeing what I love have that effect on other people is great, but then I suppose, you know, one of the great things is when, you know, earlier we talked about outcomes and it's very hard to see an outcome early on. So if I work with a young person for twelve weeks, by the end of that twelve weeks, I'll know yeah he can use Logic [music production software], and he can make a beat, or he could, you know, go in there and voice a track, probably on his own, that's great, but there's no long-term outcomes I suppose, but I-when I-for example I worked with a young person when he was-it was about 2003 or 4, when he was in a PRU [Pupil Referral Unit]. And he was 15, he was 14 actually, and he was struggling at school, he was doing really badly actually, he had a baby, and you know-but, you know, he was getting on with it, and he was passionate about music, but he was-his life was horrendous. So I saw him last week, and he's now, you know, doing live sound for bands, and he's been working a youth provision doing music on the streets, and he'shis daughter's now 11 years old and he's doing really well, and he's running a gardening business, and that's amazing, because he's still making music, he's still doing his creative things that we were doing with him when he was, you know, 14, but his life's moved on, and he's-you know, he didn't end up in prison, he didn't go down that path that, really, I thought he would have, you know, he's - ten years down the line he's turned into this amazing young person who's got it all going on. And that's what-why I love what I do, it's because, you know, you might not be able to see it straight away, you might not be able to see that amazing effect straight away but ten years down the line, when they come back to you and go "yeah, I'm still making music, you know, I do this thing with this Reggae night", that's great, and that's for me, that's what it's about, you know--.

Within this relatively short description we have the representation of personal, psychological, social impacts, we have both intrinsic and instrumental understandings of the value of the arts, and we have the construction of the interaction of these different variables into a temporally-situated narrative that centres upon one individual. The limitations of space prevent us giving further examples, but this kind of complex interaction of different schemes of value was a central part of the discourses of value of a great many of the practitioners we spoke to. Individual psychology and subjectivity, social and environmental, and the formal aesthetic qualities of the objects of practice all feature, indeed are intertwined, in practitioner's self-understandings of value. This suggests that any methodology that aims to represent practitioner perspectives on cultural value must be multi-levelled and complex. The use of rich narrative accounts that frequently focus on individuals as symbolic embodiments of the impacts of the arts and culture are, in our view, a potentially very productive way 
forward for the development of methodologies of cultural value that move beyond a straightforward intrinsic-instrumental dichotomy.

Such highly subjective narrative-symbolic representations of value are marginalised from dominant cultural evaluation practices that gravitate towards the predetermined instrumentalisation of cultural impact methodologies or the 'objective' abstractions of cultural economics. Yet narrative accounts that mobilise multiple and ambivalent determinants, "apprehended through the prism of actual experiences" (Kaszynska 2015: 5) are central to the form that the expression of value takes for cultural practitioners in our research.

\section{Conclusion}

This article has argued that official methodologies and epistemologies of cultural value form part of a public discourse that functions to structure the material practices of culture, legitimising certain ways of working, certain values, certain organisational cultures and so on, at the expense of others. But while these discourses are dominant, they do not fully define and colonise the discourses of practitioners. Rather, practitioner perspectives remain implicit, not fully visible in public discourse. We have outlined the conception of infrapolitics as a useful way to conceive of these contested power relationships in the cultural sector. The efficacy of this approach is in the reconstruction of cultural value 'from below', representing the discourses of value that correspond to relatively subordinate social actors, the hidden transcripts of cultural practice. Infrapolitics allows us to explore the extent of the marginalisation of cultural practitioners from accepted conceptions of cultural value, from the methods used to measure cultural impacts, and from cultural policy more generally. 
The particular issue we are concerned with here is the extent to which dominant forms of cultural evaluation marginalise the discourses of value that correspond to cultural practitioners themselves. Our study of the hidden transcripts of a group of participatory artists has shown that while there are clear differences between the public transcripts of cultural value and the hidden transcripts that correspond to cultural practitioners, there are also similarities, particularly around the social and psychological dimensions of value. This suggests that the understandings that underpin and formulate official representations - the public transcripts of cultural value - are not so far removed from the hidden transcripts that correspond to practitioners themselves. Furthermore, it is the intrinsic-instrumental dichotomy itself - so central to cultural policy debates - that is alien to our interviewee's understandings of value. As Lisanne Gibson has argued, it should be abandoned. Because, "not only is the instrumental/intrinsic dichotomy false but it does not assist us in thinking about the specific operations of particular programme and policy environments" (Gibson 2008: 248-9).

This conclusion provides strong evidence to support Belfiore's argument that "what makes the impact rhetoric questionable" is not the focus upon the instrumental effects of cultural and arts participation, but the "narrow and technocratic scope that 'impact' has acquired in policy thinking and practice" (Belfiore 2015 : 96). She continues:

\begin{abstract}
What makes these recent discourses of arts' socio-economic impact problematic is their rootedness in the need to instrumentally comply with public audit practices to garner legitimacy for demands over the public purse (irrespective of whether they, in fact, promote or merely muddle issues of transparency, democratic accountability and effectiveness) [...] The problem [...] lies in the way in which the attribution of value to the outcome of aesthetic encounters has become part of the technocratic machinery of cultural policy-making. (Belfiore 2015 : 96-97)
\end{abstract}

The measure of the effects of the domination of technocratic cultural policy-making lies in the discrepancies between practitioner perspectives and the demands of a competitive funding ecology. Organisations and individuals accommodate to these practices, 
pragmatically adopting them - with more or less success - as a tactic. In so doing they performatively constitute an instrumentalised epistemology of cultural value at the expense of the complexity that emerges in practitioner narrative accounts. Practitioners therefore also play an important role in the constitution of these dominant discourses in order to further their own interests, adapting them and deploying their productive capacity in a variety of ways. The efficacy of this is in leveraging a larger slice of more limited funds towards certain cultural organisations at the expense of others, and more generally to the subsidised cultural sector at the expense of other parts of the public sector.

This demonstrates Scott's (1992) argument that to understand the operations of discursive power we must explore the interactions between official and hidden transcripts; indeed, that one cannot understand the operation of dominant discourses fully without also accounting for the discourses of subordinate groups which are rarely fully represented in public. Complex interactions between personal, psychological and social impacts, and the combination of a range of instrumental and intrinsic understandings of value, are central to the subjective accounts of value of the cultural practitioners that we spoke to. But these sorts of subjective, narrative accounts are not represented in the technologies and processes of dominant forms of value and evaluation. This suggests that any attempt to fully represent the value of culture must incorporate methodologies that represent rich subjective experience in order to reconstruct the hidden transcripts of cultural value from practitioner perspectives. This is but one example, but a compelling one, to express both the power and limitations of the dominant discourses of cultural value. While elite policy actors and official constructions of value tell us much about dominant discourses, if we want to understand the operations of power we must look towards the hidden transcripts.

Notes 
1. The Culture and Sport Evidence (CASE) programme is a three-year joint programme of research led by the Department for Culture, Media and Sport (DCMS) in collaboration with the Arts Council England (Wallace), English Heritage (EH), the Museums, Libraries and Archives Council (MLA) and Sport England (SE). See http://www.culture.gov.uk/what_we_do/research_and_statistics/5698.aspx

2. The Warwick Commission on the Future of Cultural Value. See http://www2.warwick.ac.uk/research/warwickcommission/futureculture/

3. For a summary of all 70 projects funded under the Cultural Value Project scheme see: http://www.ahrc.ac.uk/documents/project-reports-and-reviews/cultural-value-project-projectsummaries/

4. CIT was developed by John Flanagan in the 1950s (Flanagan 1954) and became ubiquitous in fields such as nursing, job analysis, counselling, education, medicine, marketing, organizational learning, psychology and social work (Butterfield, Borgen et al. 2005). Through the collection of detailed observations or reports of behaviour in relation to specific, significant phenomena (critical incidents) researchers can quickly build robust and reliable understandings with a range of immediate practical applications. From the late-1980s, CIT began to be utilised in research from a social constructivist perspective (Chell 2004, Butterfield, Borgen et al. 2005). This research tended to focus upon CIT's utility to generate data on self-understandings of phenomena, and as an inductive tool to generate and develop theoretical models. Foundational in this was Lorette Woolsey who advocated CITs use in counselling psychology, with particular utility for theory and model-building (Woolsey 1986). CIT's use in the cultural sector as a measurement of impact has been criticised by Selwood (2002) as part of a more general reliance on 'soft', anecdotal evidence of the positive effects of cultural participation used in advocacy. Clearly CIT is of limited value in developing robust, systematic evidence of impact based on monitoring and evaluation. However, its usefulness as a generator of descriptive components of cultural value has not, to our knowledge, been explored. CIT is particularly appropriate for its utility to generate data on self-understandings of phenomena, and as an inductive tool to generate and develop theoretical models (Woolsey 1986, Butterfield, Borgen et al. 2005).

5. In this we have been influenced by Eleanora Belfiore and Oliver Bennett's 'determinants of impact' model of cultural impact (Belfiore and Bennett 2007).

\section{References}

Bachmann, G., J. Dovey, J. Monaco and B. Sharpe (2012). Cultural Value Networks. Bristol, Digital Cultures Research Centre, University of the West of England: 50.

Bakhshi, H., A. Freeman and G. Hitchen (2009). Measuring intrinsic value - how to stop worrying and love economics, Research Papers in Economics: 1-16. 
Banks, M. (2015). Valuing cultural industries. The Routledge Companion to the Cultural Industries. K. Oakley and J. O'Connor. London, Routledge: 35-72.

Belfiore, E. (2002). "Art as a means of alleviating social exclusion: Does it really work? A critique of instrumental cultural policies and social impact studies in the UK." International journal of cultural policy 8(1): 91-106.

Belfiore, E. (2004). "Auditing culture." International journal of cultural policy 10(2): 183 202.

Belfiore, E. (2009). "On bullshit in cultural policy, practice and research: notes from the British case." International journal of cultural policy 15(3): 343-359.

Belfiore, E. (2015 ). "'Impact', 'value' and 'bad economics': Making sense of the problem of value in the arts and humanities." Arts and Humanities in Higher Education 14(1): 95110.

Belfiore, E. and O. Bennett (2007). "Determinants of impact: towards a better understanding of encounters with the arts." Cultural Trends 16(3): 225-275.

Belfiore, E. and O. Bennett (2010). "Beyond the "toolkit approach": arts impact evaluation research and the realities of cultural policy-making." Journal for Cultural Research 14(2): 121-142.

Bowman, A., M. Moran and K. Williams. (2012). "The (Miskell)rule of the econocrats: how to re-politicise economics." Retrieved 13h Jan, 2015, from https://www.opendemocracy.net/ourkingdom/andrew-bowman-mick-moran-karelwilliams/misrule-of-econocrats-how-to-re-politicise-econom.

Bunting, C. (2010). Achieving great art for everyone: A review of research and literature to inform the Arts Council's 10-year strategic framework. London, Arts Council England.

Butler, J. (2010). "Performative agency." Journal of Cultural Economy 3(2): 147-161.

Butterfield, L. D., W. A. Borgen, N. E. Amundson and A.-S. T. Maglio (2005). "Fifty years of the critical incident technique, 1954-2004 and beyond." Qualitative Research 5(4): 475-497.

CASE (2010). Understanding the drivers, impact and value of engagement in culture and sport: An over-arching summary of the research. London, DCMS, Arts Council England (Wallace), English Heritage (EH), the Museums, Libraries and Archives Council (MLA) and Sport England (SE).

CASE (2010). Understanding the impact of engagement in culture and sport: A systematic review of the learning impacts for young people. London, DCMS. 
Caust, J. (2003). "Putting the 'art' back into arts policy making: how arts policy has been 'captured' by the economists and the marketeers." International journal of cultural policy 9(1): 51-63.

Chell, E. (2004). Critical Incident Technique. Essential Guide to Qualitative Methods in Organizational Research C. Cassell and G. Symon. London, Sage.

Cox, T. (2014). ArtWorks Evaluation Survey of Artists. Birmingham, Paul Hamlyn Foundation: 1-48.

Crossick, G. and P. Kaszynska (2014). "Under construction: Towards a framework of cultural value." Cultural Trends 23(2): 120-131.

Flanagan, J. (1954). "The critical incident technique." Psychological Bulletin 51(4): 327-358.

Frey, B. (2008). What values should count in the arts? The tension between economic effects and cultural value. Beyond Price: Value in Culture, Economics, and the Arts M. Hutter and D. Throsby. New York, Cambridge University Press: 261-269.

Gibson, L. (2008). "In defence of instrumentality." Cultural Trends 17(4): 247-257.

Grey, C. (2002). "Local government and the arts." Local Government Studies 28(1): 77-90.

Grey, C. (2007). "Commodification and instrumentality in cultural policy." International journal of cultural policy 13(2): 203-215.

Hesmondhalgh, D. and S. Baker (2011). Creative labour: Media work in three cultural industries. London, Routledge.

Hesmondhalgh, D., M. Nisbett, K. Oakley and D. Lee (2014). "Were New Labour's cultural policies neoliberal?" International journal of cultural policy: 1-18.

Hewison, R. (2012). "The benefits of the valuing culture debate, 2003-2011." Cultural Trends 21(3): 209-210.

Holden, J. (2004). Capturing cultural value: How culture has become a tool of government policy. London: Demos.

Hopkins, L. (2010). Innovation by nature: Creative industries, innovation and the wider economy. London, The Work Foundation: 1-21.

Kahn, R. (2010). "Going 'mainstream': evaluating the instrumentalisation of multicultural arts." International journal of cultural policy 16(2): 184-199.

Kaszynska, P. (2015). "Capturing the vanishing point: Subjective experiences and cultural value." Cultural Trends.

Keen, S. (2011). Debunking Economics: The Naked Emperor Dethroned? London, Zed Books. 
Matarasso, F. (1997). Use or Ornament? The social impact of participation in the arts Stroud, Comedia.

McGuigan, J. (2005). "Neo-Liberalism, Culture and Policy." International Journal of Cultural Policy 11(3): 229-241.

Merli, P. (2002). "Evaluating the social impact of participation in arts activities." International journal of cultural policy 8(1): 107-118.

Mirza, M., Ed. (2007). Culture Vultures: Is UK Arts Policy Damaging the Arts? . London, Policy Exchange.

Moor, L. and C. Lury (2011). "Making and measuring value." Journal of Cultural Economy 4(4): 439-454.

Newsinger, J. (2012). "The politics of regional audio-visual policy in England: or, how we learnt to stop worrying and get 'creative'." International journal of cultural policy 18(1): 111-125.

Newsinger, J. (2015). "A cultural shock doctrine? Austerity, the neoliberal state and the creative industries discourse." Media, Culture and Society.

O'Brien, D. (2010). Measuring the value of culture: A report to the Department for Culture, Media and Sport. London, DCMS: 1-66.

Scott, J. C. (1992). Domination and the Arts of Resistance: Hidden Transcripts. London, Yale University Press.

Selwood, S. (2002). "The politics of data collection: Gathering, analysing and using data about the subsidised cultural sector in England." Cultural Trends 12(47): 13-84.

Throsby, D. (1994). "The production and consumption of the arts: A view of cultural economics " Journal of Economic Literature 32(1): 1-29.

Throsby, D. (2001). Economics and Culture. Cambridge, Cambridge University Press.

Throsby, D. (2008). "The concentric circles model of the cultural industries." $\underline{\text { Cultural Trends }}$ 17(3): 147-164.

Vickery, J. (2007). The Emergence of Culture-Led Regeneration: A Policy Concept and its Discontents. Centre for Cultural Policy Studies Research Papers. O. Bennett and J. Ahearne. Warwick, Centre for Cultural Policy Studies.

Walmsley, B. (2012). "Towards a balanced scorecard: A critical analysis of the Culture and Sport Evidence (CASE) programme." Cultural Trends 21(4): 325-334.

Woddis, J. (2014). "Arts practitioners in the cultural policy process: spear carriers or speaking parts?" International journal of cultural policy 20(4): 496-512. 
Woolsey, L. K. (1986). "The critical incident technique: an innovative qualitative method of research." Canadian Journal of Counselling 20(4): 242-254.

1

2

3

4

5

6

7

8

9

10

11

12

13

14

15

16

17

18

19

20

21

22

23

24

25

26

27

28

29

30

31

32

33

34

35

36

37

38

39

40

41

42

43

44

45

46

47

48

49

50

51

52

53

54

55

56

57

58

59

60 
Table 1. List of evaluation practices mentioned by participants

\begin{tabular}{|c|c|c|}
\hline \multicolumn{3}{|l|}{ Evaluation practices } \\
\hline Media coverage analysis & Attendance rates/footfall & Interviews \\
\hline $\begin{array}{l}\text { Journals and diaries } \\
\text { (participants and staff) }\end{array}$ & $\begin{array}{l}\text { Self-assessment baseline } \\
\text { measures }\end{array}$ & $\begin{array}{l}\text { Case studies tracking } \\
\text { progress }\end{array}$ \\
\hline Feedback (e.g. participants, & Products of the & Parent/guardian feedback \\
\hline $\begin{array}{l}\text { partners, commissioners, } \\
\text { politicians, stakeholders) }\end{array}$ & $\begin{array}{l}\text { engagement (products, } \\
\text { music, drama etc) }\end{array}$ & Questionnaires \\
\hline Audience evaluation & Photos & \multirow{2}{*}{$\begin{array}{l}\text { Longitudinal capture of } \\
\text { participants' progress }\end{array}$} \\
\hline Financial value & Film footage & \\
\hline Social impact & Team meetings & Qualification attainment \\
\hline Social Accounts & Social media analysis & Learning plans \\
\hline Social Return On & & \\
\hline Investment & Observations & Crime rates (ASBO) \\
\hline
\end{tabular}

